The Geneva Papers on Risk and Insurance, 16 (No. 58, January 1991), 20-38

\title{
The Effects of No Fault on Automobile Insurance Loss Costs
}

\author{
by $\mathbf{J}$. David Cummins* and Mary A. Weiss**
}

\section{Introduction}

Automobile insurance premiums have been rising rapidly in the United States. During much of the 1980 s, premiums have grown at approximately three times the rate of inflation in the consumer price index (Weiss and Cummins [1989]). The high rate of premium inflation has led to political pressure to cap insurance rates, reform the legal system, and regulate auto insurers more stringently. Objective information on the causes of the problem has been difficult to obtain, and most of the insurance reform proposals have not been based on sound economic analysis.

Automobile insurance pays for two principal types of expenses: property damage and personal injuries. The latter category includes economic losses such as medical bills and lost wages and general damages for the "pain and suffering" resulting from an injury. Weiss and Cummins [1989] trace the source of the unusually high premium inflation to the severity of property damage losses (due to more technologically advanced automobiles) and the frequency and severity of personal injury claims. The present paper focuses on personal injury losses because they are more directly affected by the legal system than property damage claims.

The traditional mechanism for providing personal injury compensation to victims of auto accidents in the United States is the tort system. Under tort, drivers must show that some other party (e.g., another driver) is negligent in order to collect. If negligence is proven, the injured party can collect for medical bills, lost wages, and pain and suffering. Drivers insure against tort suits by purchasing bodily injury liability $(B I L)$ insurance.

The tort system evolved as a mechanism to provide deterrence against negligent driving and is far from optimal as a compensation system. It has been criticized as slow, inefficient,

* Wharton School, University of Pennsylvania.

** Temple University. 
and inequitable and has been shown to overcompensate small claims and undercompensate large claims (see Rand [1985]). Because of the "nuisance value" of small claims and the difficulty in proving fraud, it is alleged that the tort system fosters the filing of false and inflated personal injury suits. ${ }^{1}$ Indeed, Weiss and Cummins [1989] find that bodily injury claims frequency in tort states has risen faster than property damage claims frequency.

No fault insurance was developed as an alternative compensation system that mitigates some of the defects of the tort system. No fault has two distinguishing characteristics: (1) There is some limitation on the right to sue for personal injury losses, and (2) first-party insurance coverage is provided for economic personal injury losses (medical bills and lost wages) resulting from automobile accidents. ${ }^{2}$ Under no fault, accident victims collect their economic losses directly from their own insurers regardless of fault. The ability to sue is limited to accidents that exceed a threshold level of severity, with the threshold defined either verbally or as a monetary amount of economic damages. ${ }^{3}$ Typically, victims whose accidents satisfy the threshold can sue for pain and suffering (general damages) plus economic losses not covered by no fault (such as unusually high medical losses).

Drivers in no fault states purchase BLL coverage to protect against lawsuits from claims exceeding the threshold and personal injury protection $(P I P)$ coverage to pay their own medical and wage losses resulting from auto accidents. No fault auto insurance is present in thirteen states. Eight additional states have adopted add-on laws that combine first-party coverage (PIP) with tort but do not restrict the right to sue.

As a first-party coverage, no fault delivers economic loss payments more efficiently than tort (e.g., Harrington [1986], Witt and Urrutia [1983]). The original plan was that these administrative savings plus the pain and suffering benefits eliminated by the threshold would be reallocated to pay the higher economic loss benefits under no fault. However, depending upon the effectiveness of the threshold, no fault actually may increase the amount of benefit payments by adding first-party payments for claims that would not have been compensated under tort without proportionately reducing general damage awards ${ }^{4}$ In addition, thresholds may weaken the deterrent effect of tort, leading to higher accident rates.

Previous empirical research has addressed the impact of no fault on accident rates (Landes [1982], Kochanowski and Young [1985], and Zador and Lund [1986]) with conflicting results. The most recent U.S. research suggests that no fault has no impact on fatal accident rates, but nonfatal (injury) accidents may increase slightly due to no fault

${ }^{1}$ Empirical evidence on the existence and nature of fraudulent liability suits has recently been provided by a major study of Massachusetts auto bodily injury claims. See Automobile Insurers Rating Bureau of Massachusetts [1990].

2 With rare exceptions, no fault laws in the United States have no impact on property damage loses.

${ }^{3}$ In spite of the term "no fault", these laws might be described more accurately as "limited fault" because tort suits are restricted rather than eliminated. The Canadian province of Quebec has a law which virtually eliminates the right to sue and thus comes very close to being a no fault law in the literal sense.

${ }^{4}$ Under no fault, all victims, rather than just those with a valid tort claim, are eligible to be compensated for economic personal injury losses. 
(Cummins and Weiss [1989]). ${ }^{5}$ Research on accident rates in Quebec provides evidence of higher fatality rates under no fault in that province (Devlin [1988]). ${ }^{6}$

The purpose of this paper is to investigate the effects of no fault on the loss component of the premium. This component, known as the pure premium, is the portion of the premium used to pay losses and is sometimes referred to also as the net premium or actuarial premium. ${ }^{7}$ Most of the factors affecting auto insurance costs have their primary impact through the pure premium. ${ }^{8}$

In 1988 the pure premium for private passenger auto liability accounted for over 93 percent of auto insurance premiums earned by property-liability insurers (Best's Aggregates and Averages, 1989). Unless the net premium (augmented by investment income) is sufficient to pay covered losses, premium rate caps and restrictive regulation will severely disrupt the insurance market. Thus, analysis of the pure premium is a critical step in sorting out the auto insurance cost controversy.

Auto bodily injury liability (BIL) and personal insurance protection (PIP) pure premiums are analyzed in this paper. The objective is to determine the impact of no fault insurance and other variables on loss costs. The results should be useful in public policy discussions of automobile insurance by assisting in the evaluation of mandated premium reductions and other proposals for controlling costs.

Previous studies (e.g., AIRAC [1989], Webb and Lilly [1983], and DOT [1985]) have considered the impact of no fault on pure premiums, but the analysis provided here is more sophisticated and comprehensive because (1) the impact of important exogenous factors is explicitly controlled for, and (2) the econometric estimation technique adjusts for problems inherent in a pooled time series data base such as autocorrelation and heteroscedasticity.

The remainder of this paper is organized into four sections. Section I briefly reviews the development of no fault laws. An empirical model of auto insurance costs is outlined in Section II. The data, methodology, and results are presented in Section III. Section IV concludes the paper.

\footnotetext{
${ }^{5}$ Any icrease in accidents due to no fault in the United States cannot be traced to differences in experience rating between tort and no fault. Most experience rating under automobile insurance is based on the insurer's assessment of the culpability of the insured in an accident. Thus, shifting claims out of the tort system has little impact on experience rating, especially since liability claims actually settled in court are relatively infrequent. Experience rating under no fault operates in much the same way as experience rating under tort. In fact, expericnce rating may be more effective under no fault because the frequency of claims reported to the insurer is higher, leading to a higher level of actuarial credibility.

6 The Quebec system, adopted in 1978, adopted flat (non-experience rated) premiums and pure no fault at the same time. No fault in the United States retains experience rating based on driving records and docs not totally eliminate the right to sue. Thus, the implications of the Quebec findings for the types of no fault laws adopted in the United States are not clear.

${ }^{7}$ In statistical terminology, the pure premium is the expected value of loss, usually discounted to reflect the time-value of money.

8 The other components of the auto insurance premium are the expense loading and the profit loading. The present paper focuses on the pure premium because it is the single most important component of the premium and because expense and profit analysis are also complex and deserving of article-length treatment.
} 


\section{An empirical model of auto insurance loss costs}

As mentioned above, the personal injury component of the automobilc insurance premium consists of the present value of losses, expenses, taxcs, and the insurer's profit. ${ }^{9}$ ln tort states, the losses consist of third party bodily injury claims. In no fault and add on states, both BlL and PIP losses are included in the pure premium. A conceptual model of the premium is given below:

$$
G_{T}\left(1-\delta_{N}\right)+G_{N} \delta_{N}=\frac{\left(1-\rho_{N} \delta_{N}\right) \Theta_{T} \mu_{T}}{1-\epsilon_{T}-\pi_{T}}+\delta_{N} \frac{\Theta_{N_{N}} \mu_{N}}{1-\epsilon_{N}-\pi_{N}}
$$

where $\quad G_{T}, G_{N}=$ gross premiums for BlL and BlP, rcspectively,

$$
\begin{aligned}
\Theta_{t} \Theta_{N}= & \text { claims frequency (expected number of claims per policy) for BlL } \\
& \text { coverage with no threshold and the PIP coverage, respectively, } \\
\mu_{T}, \mu_{N}= & \text { claims severity (expected cost per claim) for pre-no-fault BIL } \\
& \text { and PIP coverages, respectively, } \\
\epsilon_{T}, \epsilon_{N}= & \text { expectcd cxpenses as a proportion of the gross premium for BIL } \\
& \text { and PIP, respectively, } \\
\pi_{T}, \pi_{N}= & \text { profit loadings as proportion of the gross premium for BIL and } \\
& \text { PIP, respectively, } \\
\rho_{N}= & \text { proportion of pre-no fault expected tort costs eliminated by the } \\
& \text { tort threshold, and } \\
\delta_{N}= & 1.0 \text { if no fault is present, zero otherwise. }
\end{aligned}
$$

In this model, discounting is ignored to focus directly on the costs. ${ }^{10}$ The pure premiums are the numerators of the ratios on the right hand side of equation (1), while the denominators provide the loadings for expenses and profit. The parameter $\rho_{N}$ is used to model the proportion of bodily injury liability costs that are eliminated by the tort theshold if no fault is present. ${ }^{11}$

No fault affects several components of the insurance premium formula in equation (1). No fault reduces tort claim frequency by eliminating some tort claims. Since these claims are relatively small, it also increases tort claim severity. However, the net effect is to reduce expected tort claim costs. The degree of the cost reduction depends upon the stringency of the threshold.

\footnotetext{
${ }^{9}$ In a competitive market, premiums would provide an unbiased estimate of the present value of expected losses, expenses, and taxes and would provide the insurer a fair expected return on equity. If insurance markets are not competitive or if regulation prevents premiums from attaining competitive levels, premiums would be a less accurate indicator of the market value of resources allocated to insurance claim payments. Although there is some controversy about the competitiveness of the automoblile insurance market, many experts helieve that the market is competitive. The tort system also assesses some benefits (such as future wage loss) by conducting a present value calculation, which may be more or less accurate than would be provided by a competitive market. These present values are part of the expected loss costs reflected in the auto insurance premium.

10 This is in no way intended to suggest that discounting is unimportant but only that introducing discounting into the present discussion would complicate the problem without adding insight.

11 This parameter also impounds the effect of any change in accident rates due to the weakening of the tort deterrent under no fault. Thus, $\rho$ will be smaller than otherwise if accident rates increase. The parameter $\Theta_{N}$ also would reflect any change in accident rates under no fault.
} 
No fault increases the gross premium by adding a new coverage, personal injury protection. This is expressed in (1) by setting $\delta_{n}=1$. The frequency of first-party no fault (PIP) claims $\left(\Theta_{N}\right)$ is greater than the frequency of tort claims $\left(\Theta_{r}\right)$ because no fault compensates some drivers who would not be able to collect under tort and because accident rates may be higher under no fault. PIP claim severity should be less than tort claim severity prior to no fault because tort claims include both economic losses and pain and suffering, while PIP claims include only economic losses. However, this effect is ambiguous because of the tendency of the tort system to overcompensate small claims and undercompensate large claims (see Rand [1985]).

Of course, the expense loading for BIL is much large than that for PIP because of the high legal and administrative costs that are incurred in settling liability claims. The profit loading under BIL may be higher as well because liability claims take longer to settle and are subject to more uncertainty than PIP claims because of the unpredictable nature of jury verdicts and the legal climate in general.

Considering only expected loss costs, no fault will reduce costs if the following condition holds: $\Theta_{N} \mu_{N}<\rho \Theta_{T} \mu_{T}$, i. e., if the additional expected costs covered under no fault are less than the tort loss costs eliminated by the threshold. Of course, even if this condition does not hold, the gross premium under no fault may be less because of the higher expense loading for BIL losses. ${ }^{12}$ The objective of this paper is to provide empirical evidence on pure premiums for personal injury coverages under tort and no fault. Thus, for tort, our dependent variable is $\Theta_{T} \mu_{T}$ and, for no fault, $(1-\rho) \Theta_{T} \mu_{T}+\Theta_{N} \mu_{N}$.

\section{Empirical evidence}

\subsection{Trends in claim costs}

Figures 1 and 2 display indices of claim frequency and claim severity by type of legal system. The graphs indicate that bodily injury liability (BIL) claim frequency in tort states has grown more rapidly than either PIP or BIL frequency in no fault states. 13 (Recall that BIL frequency in no fault states reflects claims that exceed the threshold and hence are eligible for tort.) These results are consistent with the hypothesis that moral hazard associated with the ease of collecting relatively small liability claims is an important determinant of the auto insurance cost problem. Since insurers have more incentive to resist larger liability claims, frequency inflation due to moral hazard should be less important under no fault if thresholds eliminate significant numbers of small liability claims. A similar

12 On the other hand, discounting, not reflected in equation (1), probably would have a greater effect on tort than on no fault because tort claims pay later on the average than no fault claims. Of course, later payment reduces the economic value of the payment to the recipient.

13 These data are obtained from the National Association of Independent Insurers (NAII). Claim frequency is defined as claims arising per exposure unit. The exposure units are earned car years. In theory, severity is defined as losses incurred (including incurred but not reported (IBNR) losses) divided by claims incurred. These data are unavailable from the NAII. The measure of severity used here is average paid claim costs (losses paid divided by the number of claims paid), which should provide a reasonable approximation to severity trends. 
pattern is present in claims severity; BIL severity growth in tort states exceeds PIP and BIL severity growth in no fault states. These latter results are somewhat surprising, because the presence of dollar valued threshold in no fault states leads to accelerated inflation. ${ }^{14}$

Pure premium indices are presented in Figure 3. Since tort states have higher claim frequency and severity growth rates, it is not surprising that these states have the highest pure premium growth.

These results are not conclusive evidence of a connection between type of legal system and premium inflation, because pure premiums also are affected by demographic, economic, and environmental factors which differ widely by state. Table 1 provides a statistical profile of no fault and tort states. This table indicates that states with no fault are more urbanized and characterized by higher traffic density and income per capita. Many of these factors are associated with accident rates (AIRAC [1989]). Although claim frequency and severity have been growing more rapidly in tort states, no fault states have a higher total pure premium level for bodily injury costs. The average pure premium is $\$ 67$ in tort States (and consists entirely of bodily injury liability claims) while the average pure premium is no-fault States is $\$ 141$. The total premium under no fault consists of the average BIL premium $(\$ 30)$ plus the PIP premium $(\$ 111)$.

\section{Equation Specification}

To analyze pure premiums, recognition must be given to cost factors that vary by state. The tendency of any given driving environment to generate accidents depends upon exogenous factors, such as weather and endogenous factors such as highway construction, the number and quality of automobiles, and the amount each automobile is driven. Economic and demographic variables such as income, age, and education also affect the care levels and driving skill of the population. All of these factors potentially affect both claim frequency and claim severity. The frequency and severity of claims also may be affected by the legal system. A multivariate statistical framework that explicitly controls for all these factors is needed to analyze pure premiums.

This paper uses a pooled cross-section, time-series multiple regression model to analyze the relationship between compensation systems and pure premiums. The unit of observations is the pure premium by state and by year. The equation specification is given below:

where

$$
\begin{aligned}
\text { Pure Premium }= & \beta_{0}+\beta_{I} X+\beta_{2} D+\epsilon \\
X= & \text { matrix of explanatory variables }(N T x K), \\
D= & \text { vector of qualitative }(0,1) \text { variables describing the auto accident com- } \\
& \text { pensation system }(N T x S), \\
\epsilon= & \text { random error vector }(N T x 1), \\
\beta_{I}= & \text { coefficients (or coefficient vectors) to be estimated, } i=0,1,2 .
\end{aligned}
$$

Except for qualitative variables all variables are in logarithms.

14 Inflation in premiums increases at a higher rate than inflation in loss costs because inflation affects all claims above the threshold and, in addition, pushes a higher proportion of claims over the threshold. 
Among the compensation systems that can be allowed for in the matrix $D$ are no fault, verbal no fault, and add-on. The coefficient of the no fault qualitative variable indicates the relationship between the pure premium and no fault. The stringency of the no fault threshold will affect this relationship. ${ }^{15}$ Because monetary threshold have not been updated for inflation, the effect of no fault on pure premiums may have changed over time as inflation increased the number of claims eligible for tort. An interaction term for time and no fault is included to capture this effect.

A few states use verbal threshold that eliminate lawsuits uless serious injury (e.g., permanent disfigurement) occurs. ${ }^{16}$ Such threshold are less susceptible to inflation than dollar thresholds. A dummy variable for verbal no fault is used to test for this effect.

Because pure premiums are obtained as the product of claims frequency and severity, frequency and severity indices are included as explanatory variables in the estimation equation. Meaningful claims frequency variables are difficult to construct. One statistical problem arises because no fault eliminates relatively minor claims from eligibility under the tort system. Thus, the introduction of no fault lowers BIL claim frequency rates, but this does not necessarily have implications for accidents rates. On the other hand, no fault has no direct impact on property claims arising from auto accidents. For this reason property claims rates provide a better indication of the impact of no fault on accident rates, and this type of variable is adopted as the frequency index in this study.

Three types of automobile coverages are available for property claims: property damage liability (PDL), collision, and comprehensive. Property damage liability is a third party coverage insuring the motorist against liability suits for damage he or she may cause to the property of others. This coverage is compulsory or quasi-compulsory in all states. Collision and comprehensive coverages, on the other hand, are voluntary coverages reimbursing the insured for damage to his or her automobile on a no fault basis. Collision covers damage due to auto accidents, while comprehensive covers other types of losses such as fire and theft.

The most likely effect of no fault on property claims concerns the relative attractiveness of liability and collision coverages as sources of recovery. ${ }^{17}$ The number of PDL claims may be lower under no fault because small BIL lawsuits should be restricted, and a PDL claim frequently accompanies a BIL lawsuit. Hence drivers (and lawyers) may be less likely to find it worthwhile to file PDL lawsuits, leading to a substitution of collision for PDL claims

15 An alternative is to use the dollar amount of the threshold as the variable. This approach was tested but not used in the final version of the model because the expenses that can be used to satisfy the threshold vary by state. Thus, a threshold with a higher nominal monetary value actually may be less stringent than one with a lower nominal value.

16 The verbal threshold states in this study are Florida, Michigan, and New York. New Jersey and Pennsylvania recently enacted verbal no fault laws where drivers can choose whether or not to remain under the pure tort system or opt for verbal threshold no fault coverage at reduced rates. The New Jersey and Pennsylvania laws were enacted too recently to be included in the data base.

17 Accident rates might be useful also in measuring claim frequency. However, all accidents may not be reported to the state authority compiling accident statistics. In addition, accidents do not always result in claims. Since it is claim frequency which influences pure premiums directly, claims frequency for property coverages are used in this study. 
in no fault states. ${ }^{18}$ To test for possibly differing effects, claim frequency for collision, PDL, and collision and PDL, combined are used as alternative frequency measures in this study.

BIL and PIP severity are determined by the characteristics of losses covered by auto insurance: general damages, medical expenses, and wage loss. Medical expense and income variables are included in the model and are expected to be positively related to premiums. ${ }^{19}$

The ratio of insured to registered vehicles is included as an indicator of price and availability problems in a state's auto insurance market not captured by other independent variables. ${ }^{20}$ This ratio should be inversely related to pure premiums because a higher ratio implies that loss costs are being spread over a broader policyholder base.

\subsection{The data and data sources}

Data on pure premiums are not publicly available in a single source but must be constructed using data from several sources. Our constructed pure premium variable is defined as follows:

$$
P=\frac{P W_{B I L} L R_{B I L}+P W_{N F} L R_{N F}}{Y}
$$

where

$$
\begin{aligned}
P= & \text { pure premium for a given state in a given year (state and year } \\
& \text { subscripts are suppressed), }
\end{aligned}
$$

18 A caveat is that some overlap may be present between collision and property damage liability (PDL) claims. A driver may submit a collision claim to recover quickly, but his/her insurer may later subrogate against the other driver if the latter appears to be negligent. Thus, some double counting may be present. The statistical agent (the NAII) providing the data used in this study was unable to provide conclusive information regarding the potential extent of double counting between collision and PDL claims.

${ }^{19}$ It might be argued that real rather than nominal values of monetary variables should be used. However, one of the purposes of the study is to analyze the determinants of auto insurance cost inflation. Thus, it is the connection between nominal premiums and nominal economic variables that is important here.

20) The number of insured vehicles is available from Automobile Insurance Plans Service Office AIPSO Insurance Facts, and the number of automobile registrations are available from DOT, Federal Highway Administration, Highway Statistics. These estimates may not be perfectly consistent. For example, pick-ups or vans may be insured as passenger cars and be registered as trucks or farm vehicles. No correction could be made for this.

21 Premium and loss ratio data are from A. M. Best Company, Best's Executive Data Service, while the data on written car years are from the Auto Insurance Plans Service Office (AIPSO). Data on administrative expenses are not available by state. Such expenses cannot be inferred conveniently from the loss ratios because losses are subject to random fluctuations such that the complement of the loss ratio (i. e., 1 minus the loss ratio) is not necessarily equal to expenses. In another study, the authors' provide evidence on the effects of no fault on gross premiums (Cummins and Weiss [1989]). This provides information that may permit some indirect inferences about expenses under no fault.

22 The car-year is a ratemaking variable defined as the amount of coverage exposure provided by one car insured for one year. 
The pure premium variable used in the study measures incurred loss and loss adjustment expenses per insured car year. The inclusion of loss adjustment expenses is necessitated due to the way the data are reported. However, it is standard actuarial practice to include loss adjustment expenses in pure premium calculations, and this has the advantage of enabling the model to capture part of any administrative expensc savings achieved by no fault.

The claims frequency statistics used in the study are paid claim frequencies. This is likely to result in minimal distortion because of the relatively short payout tail for property coverages. ${ }^{23}$ The paid claim frcquency rates used in this study are dcfined as:

$$
\begin{array}{ll}
\text { (4) } & F_{t}=N_{t} / Y_{t} \\
\text { where } & F_{t}=\text { paid claim frequency in pcriod } t \\
& N_{t}=\text { number of paid claims in pcriod } t, \text { and } \\
& \mathrm{Y}_{\mathrm{t}}=\text { number of earned car ycars in period } t .
\end{array}
$$

Earned car years in an accrual measure of the amount of auto insurance coverage provided during the period.

Claim frequencies by type of property coverage are obtained from the Fast Track data base maintained by the National Association of Independent Insurers (NAII). Data are reported to Fast Track by all companies that are members of the Insurance Services Office (ISO), the principal insurance rating bureau in the United States, and the NAII, which represents companies that file independently of the ISO in regulated states.

The other variables used in the study were obtained from various business and governmental sources. The definitions and sources of variables used in the study are presented in the appendix.

The cross-section, time-series data base used in estimating the model consists of twelve years of data [1975-1986] for fifty states. Since the generalized least squares procedure designed for use in the study requires complete blocks, ten states had to be eliminated due to missing values. ${ }^{24}$

\subsection{Econometric methodology}

Preliminary testing revealed the presence of autocorrelated and heteroskedastic residuals. Thus, the folloswing error structure was used to estimate equation (2):

where

$$
\epsilon_{i t}=\rho_{i} \epsilon_{i, t-1}+\mu_{i t}
$$

$$
E\left(\mu_{i t}, \mu_{i, t-1}\right)=0, E\left(\epsilon_{i t}, \epsilon_{j t}\right)=E\left(\mu_{i t}, \mu_{j t}\right)=0, i j \text {, and } \mu_{i t} \sim N\left(0, \sigma_{i}^{2}\right) \text {. }
$$

23 A better measure of claims frequency is claims incurred. Thesc are claims that are traceable to a given accident year even though the claim may be filed in a subsequent year. For example, a BIL claim may not be filed until six months or more after the accident year. For property coverages, the lag between claims arising and claims incurred is likely to be minimal since property claims are filed and settled more expediently than BIL claims. (BIL and PIP claims incurred are mavailable from the NAII). On the other hand, pure premiums are obtained from a different source, A. M. Best Co., Best's Executive Data Service $(B E D S)$, and reflect total losses incurred (i. e., claims incurred $\times$ incurred claim amount).

24 The states deleted are Alaska, Arizona, Arkansas, Georgia, Louisiana, Maryland, Massachusetts, Missouri, Rhode Island, and Vermont. 
An iterated Aitken procedure was used to correct for autocorrelated errors, where the autoregressive parameters vary by state, and for heteroskedasticity across states. The procedure is iterated until convergence. Iterated Aitken estimates approach maximum likelihood estimates as the number of iterations increases (Kmenta [1986]).

\subsection{Empirical results}

The generalized least squares results are presented in Table 2. Four specifications are reported. The specifications in columns (1), (2), and (3) include a property damage frequency variable to capture the effect of claims frequency on pure premiums. These specifications correspond to the three aceident frequency rates used in the study: collision, PDL, and the sum of collision and PDL frequency. Equations (1) through (3) are somewhat analogous to structural equations where endogenous variables such as frequency appear as explanatory variables. This does not ereate a simultaneous equations estimation problem unless pure premiums are a determinant of frequency. In research reported elsewhere, the authors found no such effect (Cummins and Weiss [1989]). Thus, in a complete system, frequency would be recursive relative to the pure premium equation. Nevertheless, a fourth specification was also estimated, which does not include a frequency variable (column (4) in Table 2). This equation should be interpreted as a reduced form.

As mentioned above, the no fault dummy variable is included by itself in the equations as well as interacted with a time trend variable. The no fault dummy variable is equal to 1 in states that have no fault with a monetary threshold and equal to zero otherwise. If collision claim frequency is used (equation (1) in Table 2), the no fault dummy variable is not significant, but this variable is significant when PDL frequency is used (equation (2) in Table 2) and when total property claims frequency is used (equation (3)). In the reduced form (equation (4)), the no fault variable is statistically significant. Thus, overall it seems reasonable to conclude that no fault increases the intercept of the pure premium equation. ${ }^{25}$

The variable representing the interaction of the no fault dummy variable with time is statistically significant in all four equations. This is consistent with the hypothesis that no fault threshold have been eroded by inflation over time, leading to higher pure premiums.

The combined results of the no fault and no fault interaction variables in all four equations strongly suggest that pure premiums are higher in states with no fault laws that have monetary thresholds than in states operating under the pure tort system. Based on the reduced form (equation (4)), pure premiums under no fault were about 7.9 percent higher than under tort at the beginnning of the sample period (1975) but were 27.6 percent higher by the end of the sample period (1986). The difference is virtually the same regardless of the inclusion of the frequency variable.

As indicated above, no fault still could be associated with lower total premiums if the administrative expense savings under no fault offset the higher pure premium. However, if the pure premium is increasing because more BIL claims are being filed (e. g., due to erosion of the threshold), administrative expense savings will be eroded along with the threshold.

25 The likely explanation for the differing significance levels of the no fault dummy variable in equations (1) through (3) is that no fault affects ineentives with regard to the filing of PDL vs. collision claims for property losses. Collision claims frequency is likely to be higher under no fault, possibly absorbing some of the effects captured by the no fault variable in the other equations. 
Even if no fault were not associated with pure prcmium increases, the total average premium under no fault would probably exceed that under tort, everything else held constant. Claimants with first party coverage receivc payment morc quickly on the average than for tort (AIRAC) [1989]). Because loss costs are discounted in detcrmining the total premium, the present value of no fault benefits should be greater than the present value of tort benefits, everything else held constant. In addition, if no fault increases accident rates then the pure premium in no fault states must increase to cover the costs of the additional accidents.

The result suggest that no fault states with a verbal threshold may have significantly lower pure premiums than tort states or no fault states with a monetary threshold. The verbal threshold dummy variable is negative in all four equations shown in Table 2 and significant when collision frequency appears in the estimation equation and in the reduccd form (equation (4)). The reduced form suggests that a verbal threshold may be associated with pure premium reductions of about 22 percent (the reductions suggested by the other equations are lower). Thus, with a verbal threshold, the original objective of no fault, reducing premiums by transferring funds from general damages and administrative costs to PIP claims, may have been achieved. These results provide some justification for the premium rate rollbacks associated with recent no fault laws. However, for the savings to be realized, the threshold must be stringent enough to eliminate all but the most serious BIL claims. ${ }^{26}$

As expected, the coefficients of the claims frequency variables are positive and significant. These are essentially frequency proxies rather than the actual frequencies embedded in the dependent variable. Hence, they can be interpreted either as structural variables or as playing somewhat the same role as the price and income variables.

The coefficients for income per capita and the proportion of the driving population insured have the hypothesized signs. As the percent of insured drivers increases, pure premiums decrease. One reason is that uninsured motorist costs decrease. Income per capita has a positive association with pure premiums, but has a lower coefficient than medical costs suggesting that medical costs are a more important determinant of losses.

Medical costs are the single most important factor in determining pure premiums. The coefficient for medical expense is significant in all four equations presented in Table 2 . These results are consistent with the finding by AIRAC [1989] that medical costs account for 70 percent of all economic loss payments. Thesc findings provide some support for proposals aimed at reducing auto premiums by allowing drivers to substitute their own health insurance for auto insurance medical benefits.

\section{Conclusion}

Auto insurance costs are becoming unaffordable for many drivers in the United States. The rescarch reported in this study examines auto insurance loss costs or pure premiums. The results indicate that legal rules can be used to hclp control auto insurance costs.

\footnotetext{
26 Verbal threshold provisions can vary significantly. Under New Jersey's verbal threshold law, for example, drivers are eligible to file tort suits for simple fractures. As a result, this law may be less effective in lowering costs.
} 
Specifically, no fault laws with strict verbal thresholds result in lower pure premiums, everything else held constant. Thus, even if no fault results in higher accident rates, cost savings can be achieved by well-designed verbal no fault systems.

Unlike verbal no fault laws, the no fault programs with monetary thresholds that have been adopted in the United States have led to increased pure premiums. At the end of the sample period [1986], premiums in monetary-threshold no fault states were about 26 percent higher than those in pure tort states. The most likely cause of these higher costs is that monetary thresholds are not as effective as verbal thresholds in eliminating liability suits. This problem is aggravated when thresholds are not revised to keep up with inflation. Higher accident rates under no fault may play a role, but it is doubtful that the minor restrictions on lawsuits embodied in these laws have had a substantial quantitative effect on costs.

Given the moral hazard effects (i.e., inflated and fraudulent claims) encouraged by automobile bodily injury liability insurance, it is doubtful if the retention of this system in its present form can be justified in the long-run. If first-party medical and wage loss benefits are to be provided through automobile insurance, high premiums are inevitable unless significant restrictions are placed on the right to sue. In automobile insurance, the moral hazard effects of tort may far outweigh its deterrent effects. Verbal no fault laws coupled with stricter criminal penalties or fines for adverse driving behavior may provide the optimal legal system for dealing with the consequences of automobile accidents. 
Table 1

Statistical profile of states by compensation system

\begin{tabular}{|c|c|c|c|}
\hline VARIABLE & NO FAULT & ADDON & TORT \\
\hline REAL INCOME PER CAPITA & $\$ 5,674$ & $\$ 5,359$ & $\$ 5,315$ \\
\hline TRAFFIC DENSITY & 0.617 & 0.473 & 0.458 \\
\hline URBAN ROADS & 0.575 & 0.455 & 0.456 \\
\hline MILES PER CAR & 12169 & 14341 & 14007 \\
\hline POP \% URBAN & 74.4 & 63.0 & 56.1 \\
\hline POP $\%>17$ & 71.6 & 71.5 & 71.0 \\
\hline ALCOHOL (gallons/capita) & 35.2 & 16.1 & 30.4 \\
\hline FATALITY RATE & 0.0255 & 0.0266 & 0.0295 \\
\hline INJURY RATE & 1.369 & 1.0677 & 1.2094 \\
\hline RESIDUAL MKT \% & 7.3 & 5.1 & 2.9 \\
\hline COLLISION FREQUENCY & 0.0974 & 0.0773 & 0.0864 \\
\hline PDL FREQUENCY & 0.0499 & 0.0485 & 0.0493 \\
\hline BIL FREQUENCY & 0.0121 & 0.0166 & 0.0160 \\
\hline BIL AVG LOSS & $\$ 9,200$ & $\$ 4,355$ & $\$ 4,296$ \\
\hline PIP AVG LOSS & $\$ 1,243$ & $\$ 1,282$ & - \\
\hline PIP PURE PREM & $\$ 30$ & $\$ 22$ & - \\
\hline BIL PURE PREM & $\$ 111$ & $\$ 72$ & $\$ 67$ \\
\hline COL / BIL CAR YEARS & 0.694 & 0.695 & 0.710 \\
\hline
\end{tabular}

Note: Sample Period is 1975 - 1986. Detailed definitions and data sources are given in the Appendix. Brief definitions: TRAFFIC DENSITY $=$ total vehicle miles driven (millions) $/ \mathrm{miles}$ of roadway, FREQUENCY = claims paid (arising for BIL and PIP) / earned car years, PDL = property damage liability, BIL = bodily injury liability, $\mathrm{COL}=$ collision, FATALITY RATE $=$ fatal accidents / [vehicles miles (millions)], INJURY RATE $=$ injury accidents / [vehicles miles (millions)], ADDON refers to states in which PIP and tort (with no threshold) exists. 
Table 2

Pure premium equations

Generalized least squares estimates

Sample period 1975 to 1986

\begin{tabular}{|c|c|c|c|c|}
\hline INDEPENDENT VARIABLE & (1) & (2) & (3) & (4) \\
\hline CONSTANT & $\begin{array}{c}0.245 \\
(0.360)\end{array}$ & $\begin{array}{c}0.638 \\
(0.929)\end{array}$ & $\begin{array}{c}0.034 \\
(0.050)\end{array}$ & $\begin{array}{c}-0.010 \\
(-0.015)\end{array}$ \\
\hline NO FAULT & $\begin{array}{l}0.008 \\
(0.231)\end{array}$ & $\begin{array}{c}0.111 \\
(2.531)\end{array}$ & $\begin{array}{c}0.061 \\
(1.514)\end{array}$ & $\begin{array}{c}0.076 \\
(2.036)\end{array}$ \\
\hline TIME * NF DUMMY & $\begin{array}{l}0.020 \\
(4.035)\end{array}$ & $\begin{array}{c}0.011 \\
(1.974)\end{array}$ & $\begin{array}{c}0.015 \\
(2.789)\end{array}$ & $\begin{array}{c}0.014 \\
(2.816)\end{array}$ \\
\hline VERBAL & $\begin{array}{c}-0.170 \\
(-4.211)\end{array}$ & $\begin{array}{c}-0.065 \\
(-0.898)\end{array}$ & $\begin{array}{c}-0.071 \\
(-1.809)\end{array}$ & $\begin{array}{c}-0.245 \\
(-6.798)\end{array}$ \\
\hline ADDO N & $\begin{array}{c}0.147 \\
(3.101)\end{array}$ & $\begin{array}{c}0.088 \\
(1.957)\end{array}$ & $\begin{array}{c}0.129 \\
(2.828)\end{array}$ & $\begin{array}{c}0.079 \\
(1.478)\end{array}$ \\
\hline COL CLAIM FREQUENCY & $\begin{array}{c}0.299 \\
(7.311)\end{array}$ & & & \\
\hline PDL CLAIM FREQUENCY & & $\begin{array}{c}0.351 \\
(7.604)\end{array}$ & & \\
\hline TOTAL CLAIM FREQUENCY & & & $\begin{array}{c}0.374 \\
(7.861)\end{array}$ & \\
\hline HOSPITAL COST & $\begin{array}{c}0.662 \\
(11.713)\end{array}$ & $\begin{array}{c}0.693 \\
(12.127)\end{array}$ & $\begin{array}{c}0.700 \\
(12.258)\end{array}$ & $\begin{array}{c}0.599 \\
(10.383)\end{array}$ \\
\hline INCOME / CAPITA & $\begin{array}{c}0.175 \\
(2.273)\end{array}$ & $\begin{array}{c}0.231 \\
(2.849)\end{array}$ & $\begin{array}{c}0.172 \\
(2.144)\end{array}$ & $\begin{array}{c}0.199 \\
(2.395)\end{array}$ \\
\hline$\%$ INSURED & $\begin{array}{c}-0.297 \\
(-5.788)\end{array}$ & $\begin{array}{c}-0.318 \\
(-5.975)\end{array}$ & $\begin{array}{c}-0.312 \\
(-5.945)\end{array}$ & $\begin{array}{c}-0.341 \\
(-6.250)\end{array}$ \\
\hline $\mathbf{R}^{2}$ & 0.824 & 0.755 & 0.785 & 0.763 \\
\hline
\end{tabular}

Note: $t$-statisties in parenthesis below each coefficient. Detailed definitions and data sources are given in the Appendix. Brief Definitions: CLAIM FREQUENCY = claims paid / earned car years, $\mathrm{COL}=$ collision, $\mathrm{PDL}=$ property damage liability, TOTAL $=$ sum of PDL and COL; NOFAULT $=1$ if no-fault law with monetary threshold exists and 0 otherwise, ADDON $=1$ if state combines PIP with tort (no threshold), VERBAL $=1$ if state has no-fault with verbal threshold, HOSPITAL COST $=$ average daily hospital charge; INCOME/CAPITA $=$ average income per capita; $\%$ INSURED $=\%$ of driving public insured. PURE PREMIUM (dependent variable) $=$ bodily injury liability and personal injury protection (PIP) pure premiums combined/earned car years. Data for all states included except AL, AZ, AR, GA, LA, MD, MA, MO, RI, and VT. All variables in natural logarithms except dumıny variables. 


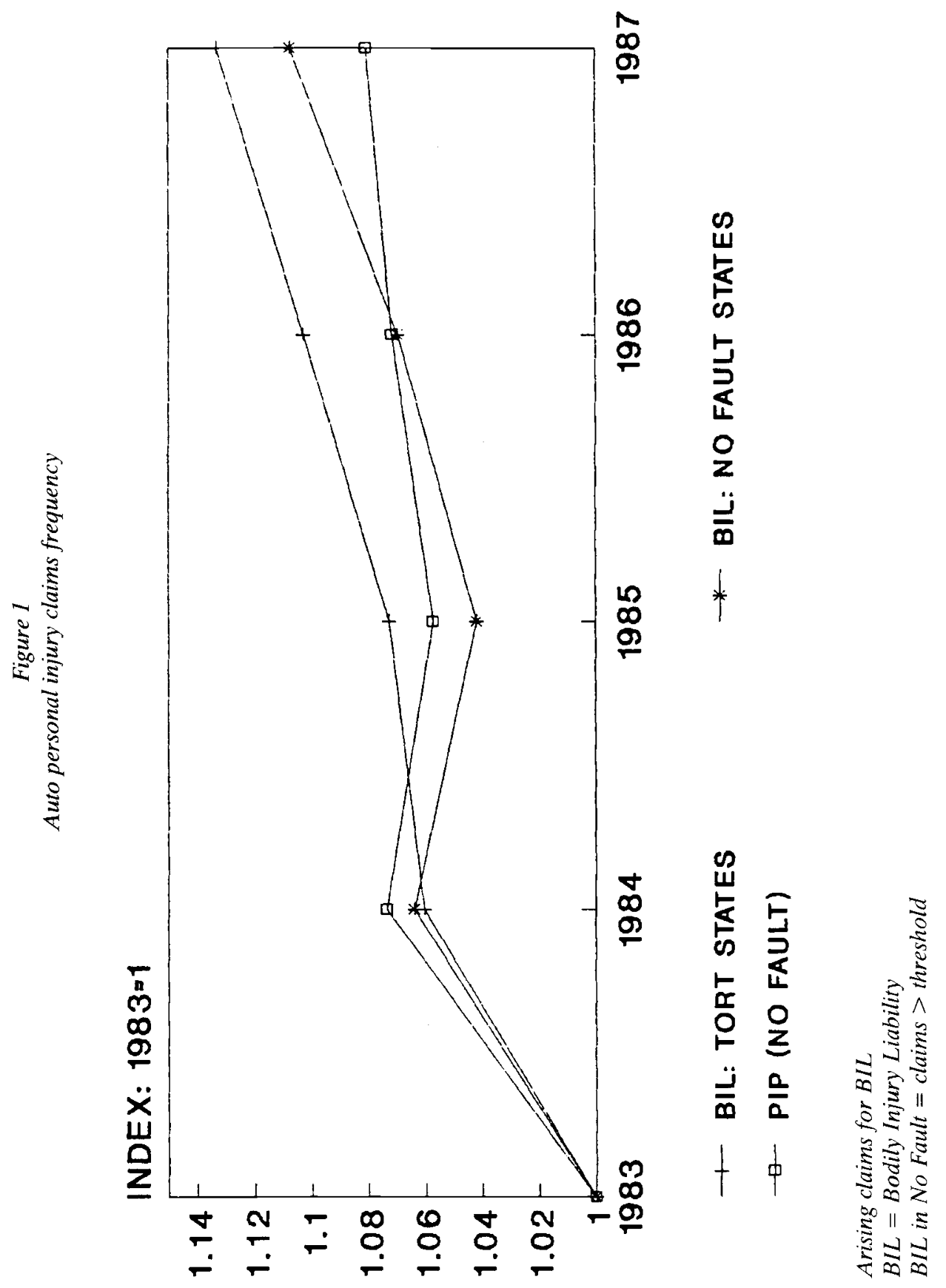




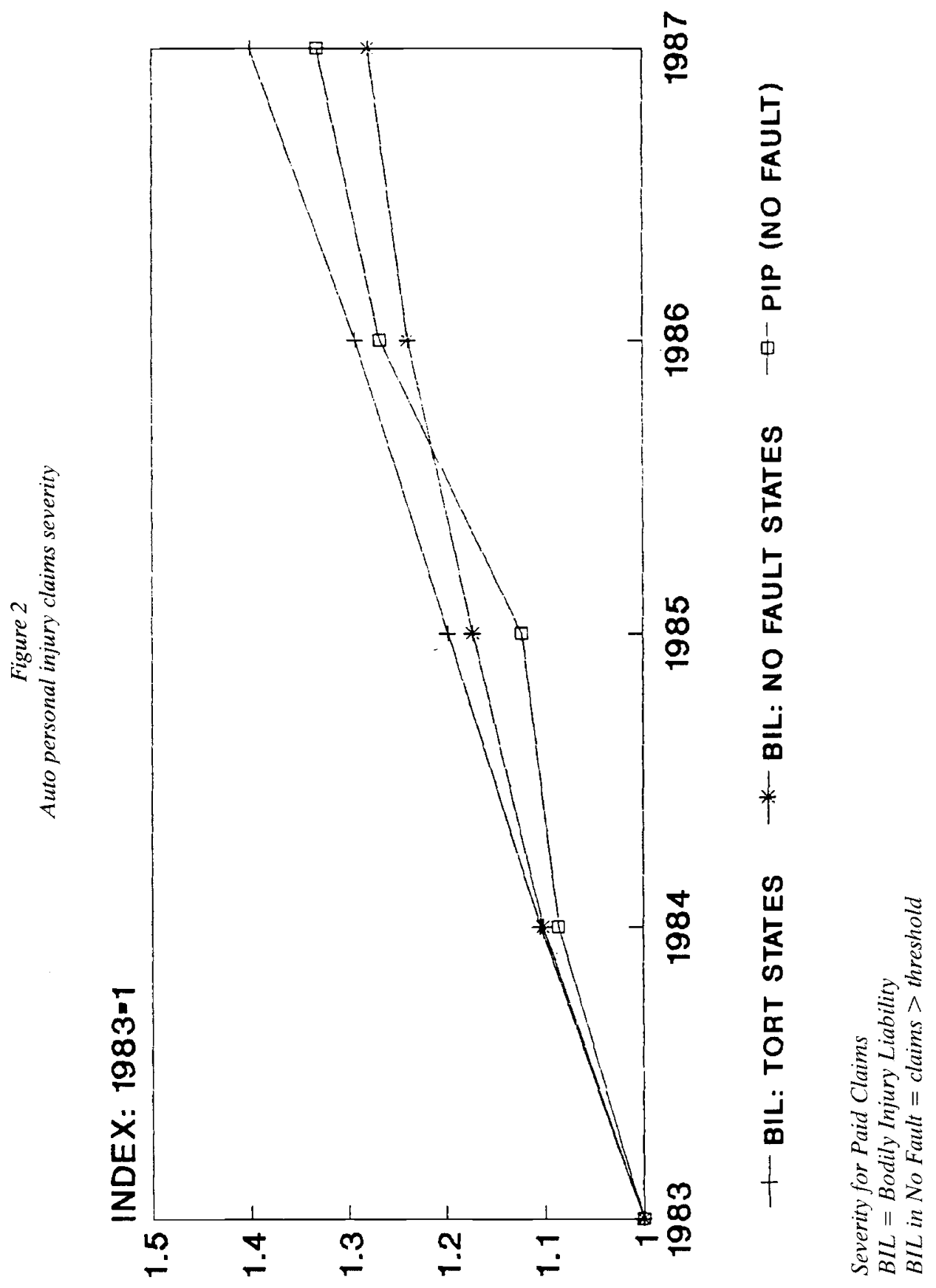




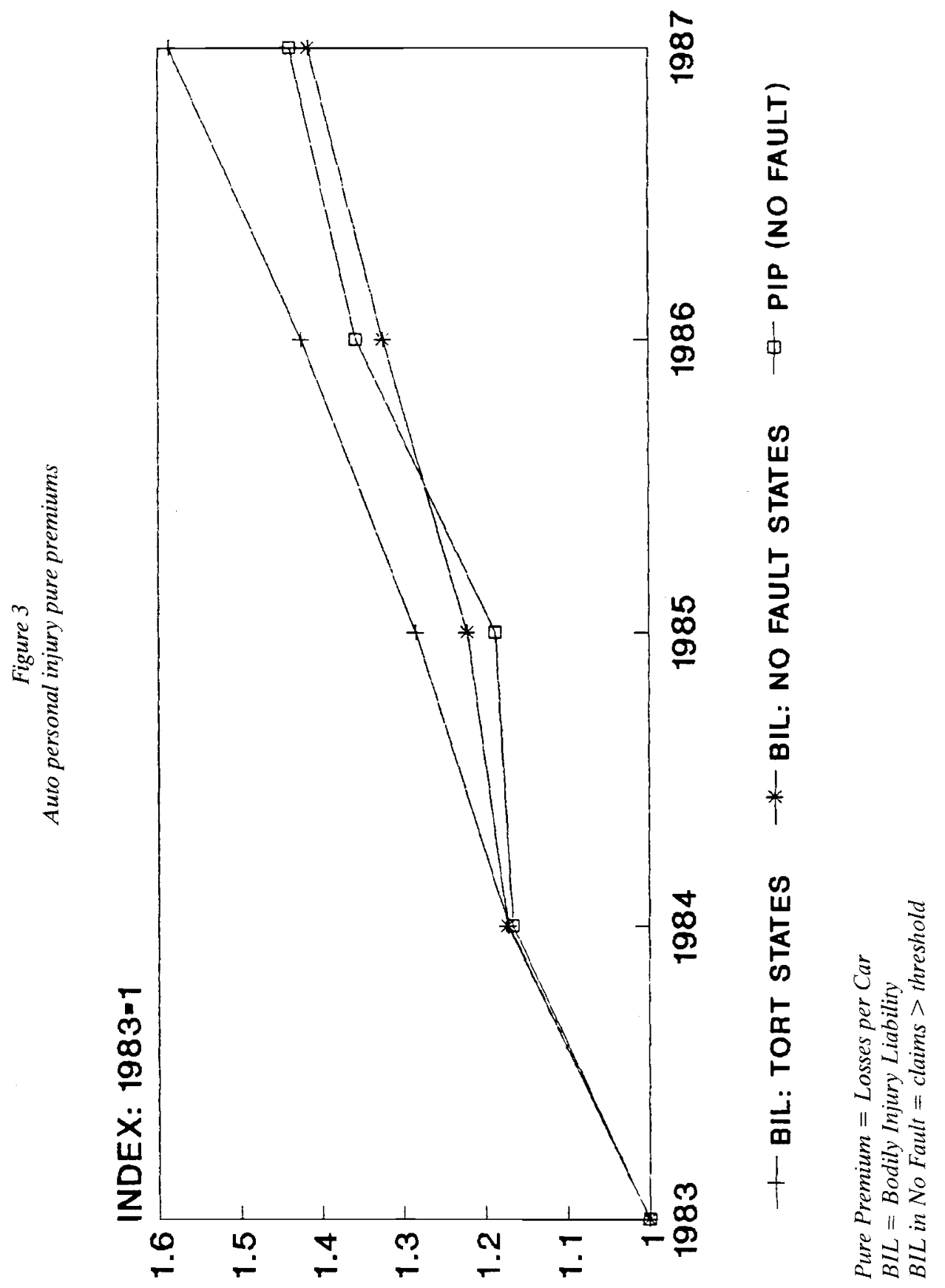


APPENDIX

Definitions and sources of variables

ADD-ON

COL CLAIM FREQ

HOSPITAL COST

INCOME/CAPITA

NO FAULT

$\%$ INSURED

PDL CLAIM FREQ

PURE PREMIUM

TOTAL CLAIM FREQ

VERBAL
Dummy variable equal to I of add-on rule exists and 0 otherwise (Rand Corp [4])

Number of collision claims arising (NAII [3])

Average daily hospital charge (DOC [5])

Average income per capita (DOC [5])

Dummy variable equal to 1 if no fault law with monetary threshold exists, and 0 otherwise (Rand [4])

Number of cars insured divided by the number of auto registrations (AIPSO [1] and FHWA [6])

Number of property damage liability claims arising (NAII [3])

Bodily injury liability and PIP pure premiums combined/earned car years (BEDS [2] and AIPSO [1])

Total number of collision and PDL claims arising (NAII [3])

Dummy variable equal to 1 if verbal threshold exists and 0 otherwise (Rand Corp [4])

Note: All variables are in natural logarithms except for dummy variables. The following abbreviations are used in the source descriptions:

$\begin{array}{ll}\text { AIPSO } & \text { Automobile Insurance Plan Service Office } \\ \text { BEDS } & \text { Best's Executive Data Service } \\ \text { NAII } & \text { National Association of Independent Insurers } \\ \text { DOC } & \text { U.S. Department of Commerce } \\ \text { FHWA } & \text { U.S. Federal Highway Administration }\end{array}$

Sources:

1. Automobile Insurance Plan Services Office. AIPSO Insurance Facts. New York, various years.

2. A. M. Best Co. Best's Executive Data Service. Oldwick, NJ.

3. National Association of Independent Insurers. Fast Track Monitoring System, Des Plaines, IL, various years.

4. Rand Corporation. Auto Accident Compensation, Santa Monica, CA, 1985.

5. U.S. Department of Commerce. Statistical Abstract of the U.S., Washington, D.C., various years.

6. U.S. Federal Highway Administration. Highway Statistics. Washington, D.C., various years. 


\section{REFERENCES}

All-Industry Research Advisory Committee (1989). Compensation for Automobile Injuries in the United States. Chicago: Alliance of American Insurers.

Automobile Insurers Rating Bureau of Massachusetts (1990), Automobile Insurance Bodily Injury Liability Fraud Study. Boston, MA.

American Insurance Association (1987). Summary of Selected State Laws and Regulations Relating to Automobile Insurance. New York.

Automobile Insurance Plans Service Office (1986). AIPSO Insurance Facts. New York.

BOYER, Marcel and DIONNF, Georges (1985). "The Economics of Road Safety". Working Paper No. 437, Centre de recherche sur les transports, University of Montreal.

BRUCE, Christopher J. (1984). "The Deterrent Effects of Automobile Insurance and Tort Law: A Survey of the Empirical Literature". Law and Policy 6, No. 1 (January): 67-I00.

CUMMINS, J. David and HARRINGTON, Scott E. (1987). "The Impact of Rate Regulation in U.S. Property-Liability Insurance Markets: A Cross-Sectional Analysis of Individual Firm Loss Ratios". Geneva Papers on Risk and Insurance, 12 No. 42 (January): 50-62.

CUMMINS, J. David and WEISS, Mary A. (1989). "An Economic Analysis of No Fault Automobile Insurance". Working paper, University of Pennsylvania, October 1989.

CUMMINS, J. David (1990). "The Stochastic Dominance of No Fault Automobile Insurance". Working paper, University of Pennsylvania, October 1990.

DANZON, Patricia M. (1986). "The Frequency and Severity of Medical Malpractice Claims: New Evidence". Law and Contemporary Problems 49 (Spring): 57-84.

DEVLIN, Rose Anne (1988). "Liability Versus No Fault Automobile Insurance Regimes: An Analysis of the Experience in Quebec", Ph. D. dissertation, University of Toronto, Toronto, Ontario, Canada.

HARRINGTON, Scott and FIELDS, Joseph (1986). "Interest Group Pressure and Political Influence: The Case of No-Fault Automobile Insurance Legislation". Working paper, University of Pennsylvania.

KIMBALL, Spencer (1985). "The Context of 'No-Fault'" Journal of Risk and Insurance (December): 662-666.

KMENTA, Jan (1986). Elements of Econometrics 2d. ed. New York, Macmillan Publishing Co.

KOCHANOWSKI, Paul S. and YOUNG, Madelyn V. (1985). "Deterrent Aspects of No-Fault Automobile Insurance: Some Empirical Findings". Journal of Risk and Insurance 52 (June): 269-288.

LANDES, Elisabeth M. (1982). "Insurance, Liability, and Accidents: A Theoretical and Empirical Investigation of the Effect of No-Fault Accidents". Journal of Law and Economics 25 (April): 49-65.

PAULY, Mark, KUNREUTHER, Howard and KLEINDORFER, Paul (1986). "Regulation and Quality Competition in the U.S. Insurance Industry". In Jorg Finsinger and Mark Pauly, eds., The Economics of Insurance Regulation. New York: St. Martin's Press.

Rand Corporation (1985). Automobile Accident Compensation. 4 vols. Santa Monica, CA.

ROLPH, John E., HAMMITT, James K. and HOUCHENS, Robert L. (1985). "Automobile Accident Compensation: Who Pays How Much How Soon?" Journal of Risk and Insurance 52 (December): 667-685.

SHAVELL, Steven (1987). Economics Analysis of Accident Law. Cambridge, MA: Harvard University Press.

United States, Department of Transportation (DOT) (1988). Compensating Auto Accident Victims: A Follow-up Report on No-Fault Auto Insurance Experiences. Washington, D.C.: U.S. Government Printing Office.

WEBB, Bernard L. and LILLY III, Claude C. (1983). "No-Fault: A Review of its Cost". Journal of Insurance Regulation 2 (December): I76-203.

WEISS, Mary A. and CUMMINS, J. David (1989). "The Auto Insurance Crisis and Solutions: Competing for Efficiency". Contingencies 1 (September-October): 46-51.

WITT, Robert C. and URRUTIA, Jorge (1983). "A Comparative Econonnic Analysis of Tort Liability and No Fault Compensation Systems in Automobile Insurance". Journal of Risk and Insurance 50 (December): 631-669.

ZADOR, Paul and LUND Adrian (1986). "Re-Analysis of the Effects of No-Fault Auto Insurance on Fatal Crashes". Journal of Risk and Insurance 53 (June): 226-24l. 